\title{
Maher M. Anous, Paul
}

\section{Jackson}

Received: 1 April 2010 /Accepted: 1 April 2010 /Published online: 26 June 2010

(C) Springer-Verlag 2010

The first unusual aspect of this book is the title. It is difficult to know why it was chosen-PAUL. It took me several years and correction of many craniofacial deformities and thought-to-be-unresectable skull base tumor resections before I was brave enough to address Doctor Tessier as Paul! I now have the best quote I could have wished for in relation to Doctor Tessier's assessment of craniofacial surgeons. His direct quotation was, "Ian Jackson has the best results in all of North America."

The book is easy to read and provides lots of information about the "original" craniofacial team. There are also vignettes related to other plastic surgeons. There is a system of "notes" at the back of the book which fills 35 pages. This is followed by interesting correspondence from several well-known plastic surgeons (Daniel Marchac, Paul
Tessier, Tony Wolfe), who had manuscripts sent to them for comments prior to publication. These make for interesting reading; the authors have not pulled any punches!

I enjoyed the final 24 pages which are photographs. A number of old friends who appear here help to bring back good memories. This book can be read very quickly, and for those of us who have spent time with Paul and the other Parisian craniofacial surgeons, it will make for interesting reading.

The only significant "problem" is the dust cover which shows a very unflattering photograph of Paul. It is a side-on view-wrinkled neck and chin with a cigar stuck in his mouth and a Coronna packet in his shirt pocket! This, together with the title, may not attract many buyers.

I. Jackson $(\bowtie)$

Novi, MI, USA

e-mail: eurjplastsurg@juno.com 